\title{
Project of an Earth Station for the Brazilian Scientific Nanosatellite (NANOSATC-BR)
}

\author{
Ândrei Camponogara [1], Igor Freitas Fagundes [2], Pawel Rozenfeld [3], Nelson Jorge Schuch [1],
} Natanael Rodrigues Gomes [4], Dimas Irion Alves [1].

[1] Southern Regional Space Research Center - CRS/CCR/INPE - MCT in collaboration with the Santa Maria Space Science Laboratory- LACESM/CT - UFSM, Santa Maria, RS, Brazil, (acamponogara@lacesm.ufsm.br); [2] Center for Telecommunications Studies, Catholic University of Rio de Janeiro (CETUC/PUC- Rio), Rio de Janeiro, RJ, Brazil; [3] National Institute for Space Research - CRC/INPE, São José dos Campos, SP, Brazil; [4] Electronic and Computing Department and Santa Maria Space Science Laboratory, ((DELC-LACESM)/CT/UFSM), Santa Maria, RS, Brazil.

Copyright 2011, SBGf - Sociedade Brasileira de Geofísica

This paper was prepared for presentation during the $12^{\text {th }}$ International Congress of the Brazilian Geophysical Society held in Rio de Janeiro, Brazil, August 15-18, 2011.

Contents of this paper were reviewed by the Technical Committee of the $12^{\text {th }}$ International Congress of the Brazilian Geophysical Society and do not necessarily represent any position of the SBGf, its officers or members. Electronic reproduction or storage of any part of this paper for commercial purposes without the written consent of the Brazilian Geophysical Society is prohibited.

\section{Abstract}

The Mission NANOSATC-BR aims to get scientific data of the regions at South Atlantic Magnetic Anomaly (AMAS) and at the Equatorial Ionosphere Electrojet on the Brazilian Territory (Schuch, 2008), employing a nanosatellite, which is characterized by its small size, form of a cube, weighting about $1 \mathrm{~kg}$ and edges with $10 \mathrm{~cm}$ (pattern CubeSat).

An Earth Station has been studied to communicate with nanosatellite. Two solutions were evaluated for implementation: The first is to acquire a complete station with a specialized company; the second option is the construction of an Earth Station in the laboratory, applying equipment used by radio amateurs.

In this paper is discussed the process used to develop the second solution, with emphasis on the construction and/or use of antennas Yagi-Uda, mainly because it is cheaper and easy to implement. Moreover, the second solution allows the application of knowledge acquired in academy.

The main objective is to determine the best antenna, evaluating the angle of half power, gain, impedance and costs.

\section{Introduction}

The Earth Station Tracking and Control NANOSATC - BR will be implemented at the headquarters of the Southern Regional Space Research (CRS/CCR/INPE - MCT), in collaboration with the Santa Maria Space Science Laboratory (LACESM/CT - UFSM).

It has been researched an appropriate architecture for the station, intending to establish the communication link with the nanosatellite of the Project and also enabling the tracking of satellites operating in VHF and UHF amateur radio band. Such architecture consists of a computer, a radio transceiver (which operates in the UHF and VHF), a rotor and an antenna (in this case, Yagi-Uda).

Since the transmission power of the satellite is low, it is necessary to improve the signal reception by Earth Station evaluating the different settings of Yagi-Uda.

\section{Method}

The antennas used to receive satellite signals present circular polarization, high gain and half power angle, between $40^{\circ}$ and $60^{\circ}$, aiming a better tracking of satellites. The antenna gain take into account the intensity of the transmitted signal and the noise intensity.

The antennas suited to the specifications are the Yagi-Uda type, mainly because its directivity and low cost.

For the design of Yagi-Uda we used the method published in Technical Report 688 of the National Bureau of Standards (NBS), entitled Yagi Antenna Design (1976). This document presents information with graphics and tables, making easier the design of practical antennas of $0.2 \lambda$ to $4.2 \lambda$ length, for operation on HF, VHF and UHF.

\section{Yagi-Uda antennas}

The first antenna studied was a 12 elements antenna, mainly because its directivity. The dimensions obtained are presented in Table I. The elements were calculated assuming aluminum profiles of $3 / 8$ inch square, with support of one inch.

Table I -Dimensions of the Yagi-Uda antenna with 12 elements.

\begin{tabular}{|c|c|c|}
\hline Element & Length & Spacing \\
\hline Reflector $(R)$ & $1.010 \mathrm{~m}$ & $\mathrm{R}-\mathrm{A}=0.411 \mathrm{~m}$ \\
\hline Feeder $(\mathrm{F})$ & $0.967 \mathrm{~m}$ & $\mathrm{~A}-\mathrm{D} 1=0.411 \mathrm{~m}$ \\
\hline Director $(\mathrm{D} 1)$ & $0.923 \mathrm{~m}$ & $\mathrm{D} 1-\mathrm{D} 2=0.411 \mathrm{~m}$ \\
\hline Director (D2) & $0.881 \mathrm{~m}$ & $\mathrm{D} 2-\mathrm{D} 3=0.411 \mathrm{~m}$ \\
\hline Director (D3) & $0.863 \mathrm{~m}$ & $\mathrm{D} 3-\mathrm{D} 4=0.411 \mathrm{~m}$ \\
\hline Director (D4) & $0.840 \mathrm{~m}$ & $\mathrm{D} 4-\mathrm{D} 5=0.411 \mathrm{~m}$ \\
\hline $\begin{array}{c}\text { Directores (D5- } \\
\text { D10) }\end{array}$ & $0.824 \mathrm{~m}$ & $\begin{array}{c}\mathrm{D}_{\mathrm{n}-1}-\mathrm{D}_{\mathrm{n}}(6 \leq \mathrm{n} \leq 10) \\
=0,411 \mathrm{~m}\end{array}$ \\
\hline
\end{tabular}


Another antenna studied, provided by Radio Astronomy Project, is a 10 elements, operating at VHF frequency range of satellite radio amateur $(151.5 \mathrm{MHz})$. The feeder of this antenna consists of a folded dipole. The Table II shows the dimensions of the used antenna. In this case, the objective was to evaluate the gain of the antenna for signal reception.

Table II -Dimensions of the Yagi-Uda antenna with 10 elements, provided by the Radio Astronomy Project.

\begin{tabular}{|c|l|c|}
\hline Element & Length & Spacing \\
\hline Reflector (R) & $0.955 \mathrm{~m}$ & $\mathrm{R}-\mathrm{A}=0.400 \mathrm{~m}$ \\
\hline Feeder (F) & $0.840 \mathrm{~m}$ & $\mathrm{~A}-\mathrm{D} 1=0.163 \mathrm{~m}$ \\
\hline Director (D1) & $0.836 \mathrm{~m}$ & $\mathrm{D} 1-\mathrm{D} 2=0.235 \mathrm{~m}$ \\
\hline Director (D2) & $0.836 \mathrm{~m}$ & $\mathrm{D} 2-\mathrm{D} 3=0.498 \mathrm{~m}$ \\
\hline Director (D3) & $0.827 \mathrm{~m}$ & $\mathrm{D} 3-\mathrm{D} 4=0.400 \mathrm{~m}$ \\
\hline Director (D4) & $0.817 \mathrm{~m}$ & $\mathrm{D} 4-\mathrm{D} 5=0.600 \mathrm{~m}$ \\
\hline Director (D5) & $0.815 \mathrm{~m}$ & $\mathrm{D} 5-\mathrm{D} 6=0.600 \mathrm{~m}$ \\
\hline Director (D6) & $0.810 \mathrm{~m}$ & $\mathrm{D} 6-\mathrm{D} 7=0.600 \mathrm{~m}$ \\
\hline Director (D7) & $0.800 \mathrm{~m}$ & $\mathrm{D} 7-\mathrm{D} 8=0.425 \mathrm{~m}$ \\
\hline Director (D8) & $0.793 \mathrm{~m}$ & - \\
\hline
\end{tabular}

The elements are presented with circular profiles of aluminum $3 / 8$ inch and the support is made with a square profile of one inch aluminum.

"Radio Astronomy Project - RA Project, aimed to build a Radio Interferometer of Aperture Synthesis with the Earth rotation, long baseline, 5 to $8 \mathrm{~km}$ - direction East / West, operating at low frequencies, centered at $150 \mathrm{MHz}$ (SCHUCH et al, 1997).

\section{Partial Results}

The Fig. 1 shows the horizontal $(\mathrm{H})$ and vertical $(\mathrm{V})$ radiation diagrams obtained with the simulation of the linear array antennas using simple dipole.

The expected gain for the linear arrangement was $14.41 \mathrm{dBi}$, as specified by the method. But the simulation showed $14 \mathrm{dBi}$. However, this value is within the margin of precision presented by the method that is $0.5 \mathrm{~dB}$. The angle of half power, showed on the simulation, was approximately $40^{\circ}$ and impedance of approximately $(22.9+\mathrm{J} 19,5) \Omega$.
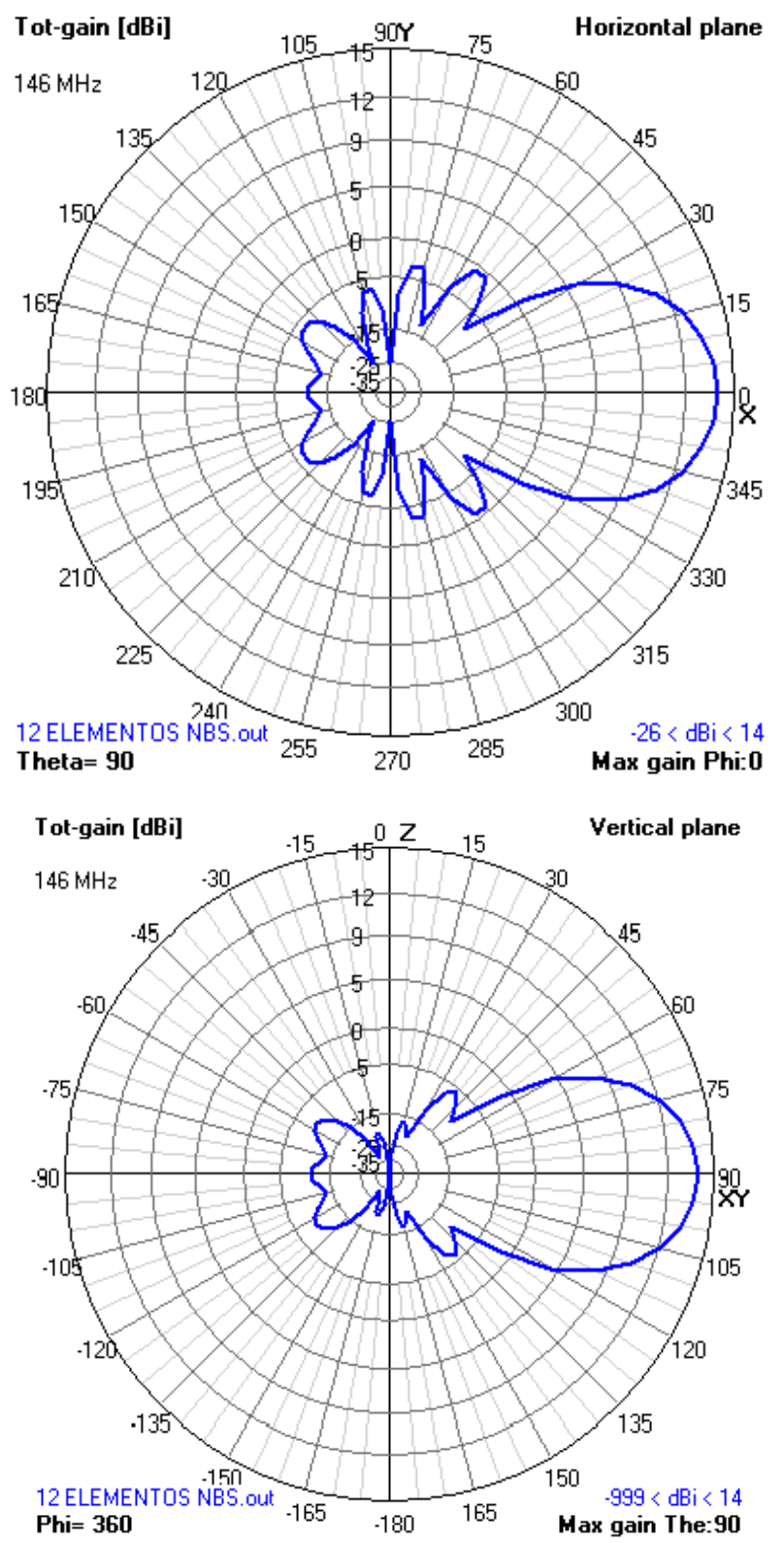

Fig. 1. Radiation diagrams of Yagi-Uda antenna of 12 elements obtained by the 4-NEC2 application using a simple dipole feeder.

The NBS practical design presents specifications considering the folded dipole. Because of that, simulations were made to observe the change of the radiation diagrams. The values of gain and impedance are close to that expected for the simulation 4NEC-2, as shown in Fig. 2, where the gain of $14 \mathrm{dBi}$ and the impedance was approximately $(113+\mathrm{j} 242) \Omega$. 

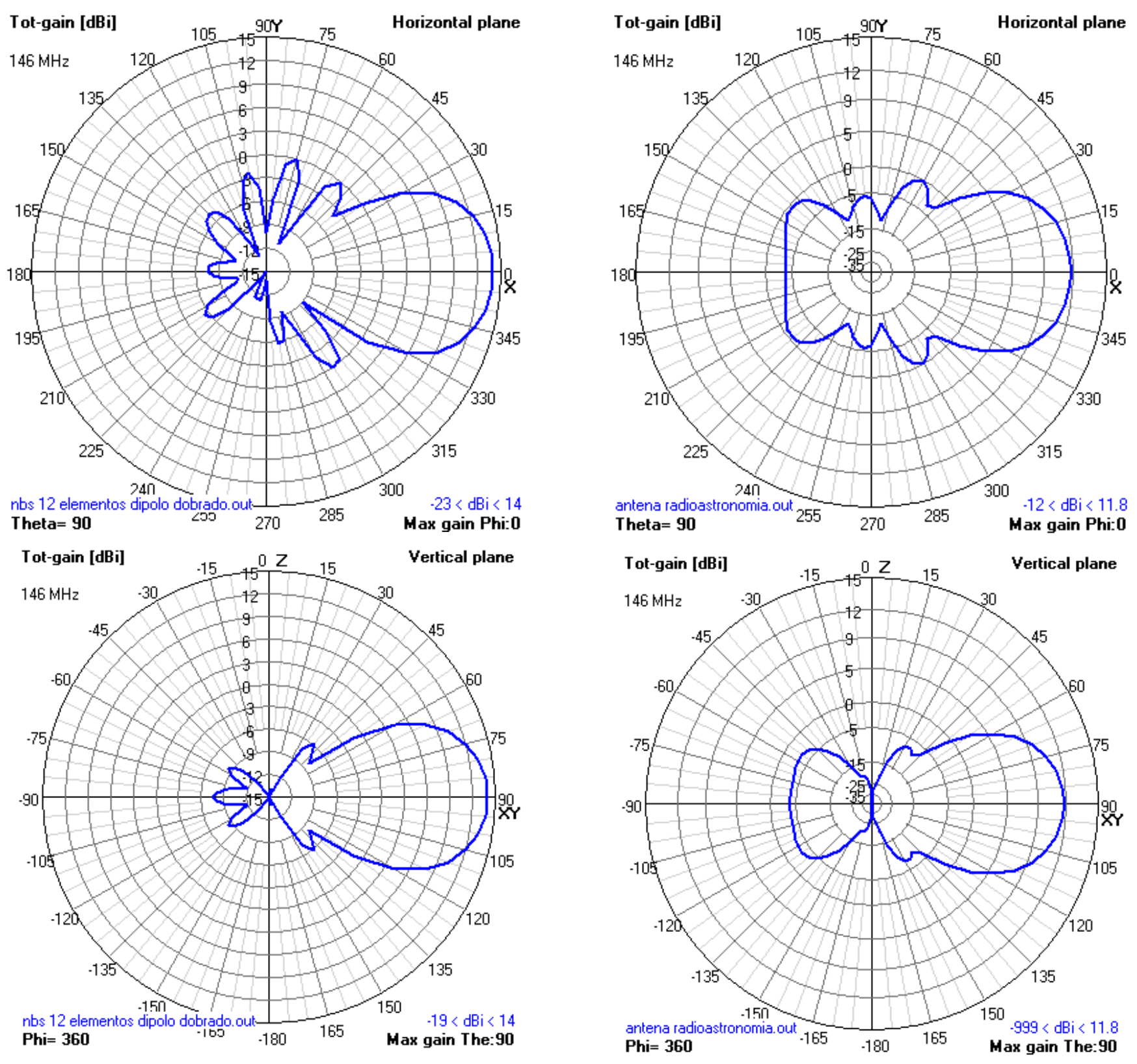

Fig. 2. Radiation diagrams of Yagi-Uda antenna of 12 elements obtained by the 4-NEC2 application using simple dipole feeder.

Also, it has been taken simulations to evaluate the performance of the antennas of Radio Astronomy Project, operating at the VHF $(146 \mathrm{MHz})$ frequency range of satellite radio amateurs.

To observe the behavior of the arrangement with different feeders, two simulations were done using a simple dipole (Fig. 3) and a folded dipole (Fig. 4).

Fig. 3. Radiation diagrams of Yagi-Uda antenna of 10 elements of the Radio Astronomy Project obtained by the 4NEC2 application using a simple dipole feeder.

The simulation showed $11.7 \mathrm{dBi}$ of gain and (22 - J93) $\Omega$ of impedance, with the simple dipole feeder. Using a center frequency of $146 \mathrm{MHz}$. The half power angle found was $50^{\circ}$. 

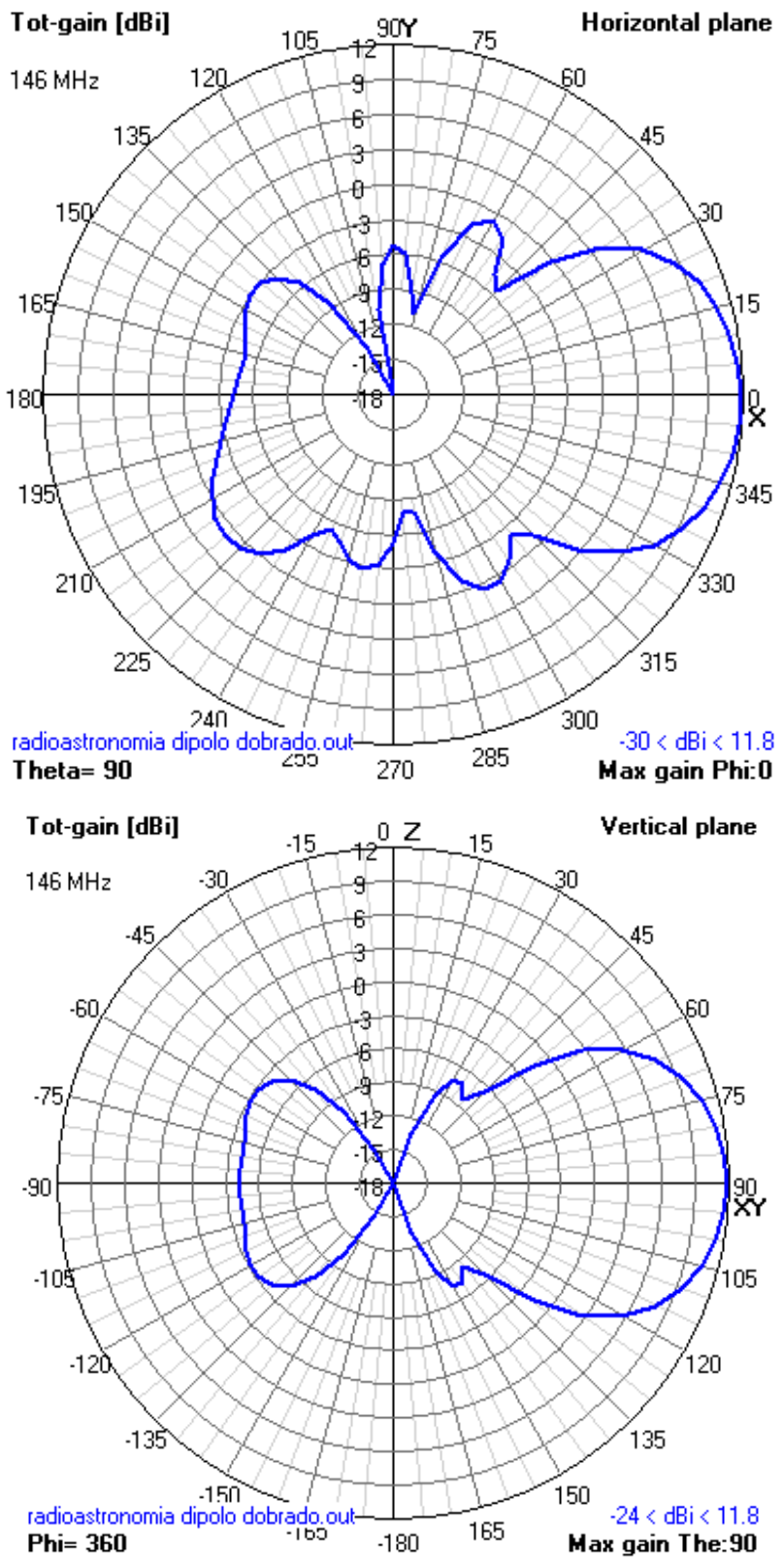

Fig. 4. Radiation diagrams of Yagi-Uda antenna of 10 elements of the Radio Astronomy Project obtained by the 4NEC2 application using a folded dipole feeder.

It was observed that the gains obtained, using the folded dipole, are similar with the simple dipole. The difference remains in a distortion of the secondary lobes on the Radiation diagrams. The distortion was caused by the element part of folded dipole, which originates an angle of $90^{\circ}$ with the antenna direction. The average impedance obtained was approximately $(120$ - j113) $\Omega$ for the simulation with the folded dipole with center frequency of $146 \mathrm{MHz}$

\section{Works in development}

The combination of two linearly polarized waves, one vertical and one horizontal, with the same amplitude and electrically $90^{\circ}$ out of phase, results in a circularly polarized wave. The Fig. 5 shows a representation of the combination of two linearly polarized waves, vertical and horizontal, $90^{\circ}$ out of phase.

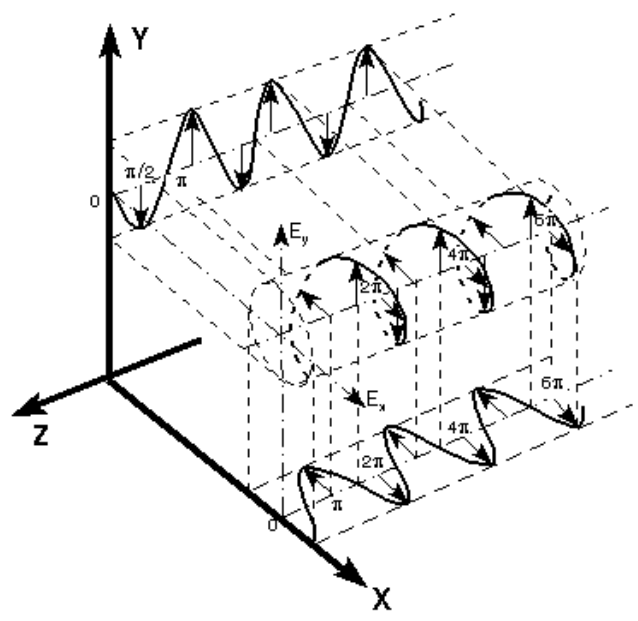

Fig. 5. Combination of two linearly polarized waves, $V$ and $H, 90^{\circ}$ out of phase. Source: (PY4ZBZ, 2008).

According PY4ZBZ, there are two methods to obtain circular polarization from Yagi-Uda: (i) placing two antennas crossed at $90^{\circ}$ without longitudinal slip and feeding them with a signal phased off by $90^{\circ}$, or (ii) feed the dipoles in phase, but shifting one of dipoles of $1 / 4$ wave $(\lambda / 4)$ along the direction of propagation.

The method to connect linear array antennas with no displacement of the elements (i) is shown in Fig. 6, which allows the variation of left and right circular polarizations. The cable of $1 / 4$ wave of $50 \Omega$ provides the phase difference required to obtain the circular polarization.

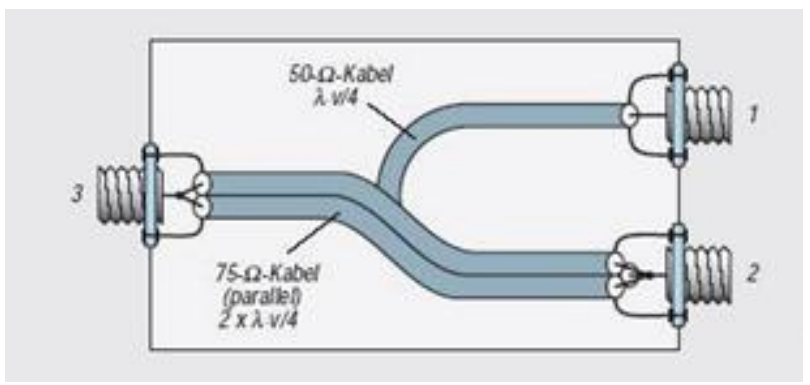

Fig. 6. Circuit for connecting cross linear antennas. Source: (PY4ZBZ, 2008).

The circuit used for circular polarization presented above provides the following characteristics: 
a) Right Hand Circular Polarization - RHCP: connector horizontal plane in 1, connector vertical plane in 2 and connector for the transceiver in 3.

b) Left Hand Circular Polarization - LHCP: connector horizontal plane in 2, connector vertical plane in 1 and connector for the transceiver in 3.

The use of this circuit requires an impedance of $50 \Omega$ for the antennas. On this project, the antenna of Radio Astronomy Project has been adjusted at the frequency of $146 \mathrm{MHz}$ using for the impedance matching a simple stub and for the balancing a 1:1 balun.

The Yagi-Uda antennas with cross shape, were used in order to obtain circular polarization. The design of a simple stub for impedance matching was developed with assistance from the Smith Chart and considering a complex impedance of (120 - j113) $\Omega$, obtained from simulations with 4NEC2 application. This value was close to that obtained with practical measurement. The dimensions of the line segments $\mathrm{L} 1$ and $\mathrm{L} 2$ designed are shown in Fig. 7.

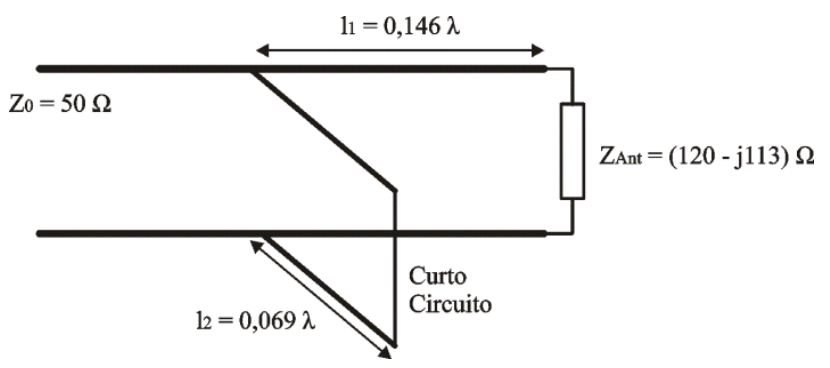

Fig. 7. Dimensions of the line segments 11 and 12 of simple stub designed for impedance matching of the antenna of Radio Astronomy Project.

\section{Conclusions}

The first conclusion from the analysis of Yagi-Uda is that the implementation of both antennas, using the radiating element as simple dipole or folded dipole, suit the specification of project. The chosen design for the antenna is the one from radio astronomy, which is already implemented in the laboratory.

Furthermore, we studied a way to implement the circular polarization, using cross Yagi-Uda-antennas, which have been implemented in the laboratory. Tests are underway with the circuit shown in Fig. 6 in order to verify the performance of such an implementation.

\section{Acknowledgments}

We thank the Program PIBIC / INPE - CNPq / MCT for the approval of the Research Project and the Organizing Committee of the 12th CISBGf the opportunity to present results of this work.

\section{References}

Fagundes, I. F; Rozenfeld, P.; Schuch, N. J.; Gomes, N. R.. Desenvolvimento de uma Estação Terrena (ET) para o Nano-Satélite Científico Brasileiro - NANOSATC - BR. (2010, july).

PY4ZBZ. (2010, May 26). Polarização de Ondas. Available: http://www.qsl.ne

Schuch, N. J. et al. Projeto Básico Missão NANOSATC - BR - Clima Espacial: Versão Um, 2008. $63 \mathrm{p}$.

Schuch, N. J.; Adaime S. F.; Oliveira, N. U. V.; Bortolotto, E.; Sarkis, P. J.; Pinheiro, D. K.; Lüdke, E.; Wendt, F. A.; Trivedi, N. B.; Costa, J. M.; Kirchhoff, V. W. J. H.; Dutra, S. L. G.; Sobral, J. H. A.; Abdu, M. A.; Takahashi, H.. O Observatório Espacial do Sul. Rev. Bras. Geof. vol.15 no.1 São Paulo Mar. 1997.

Viezbicke, P. P. Yagi Antenna Design. NBS-Technical Note 688, 1976. 30 p. 